\title{
Investigation on Thermal Changes of Workpiece in Cool Air Grinding with Porous Metal Bonded Diamond Wheel ${ }^{*}$
}

\author{
Son Hoanh TRUONG ${ }^{* *}$, Yoshitada ISONO ${ }^{* * *}$ and Takeshi TANAKA $* *$
}

\begin{abstract}
This investigation deals with the rate of heat transferred to the workpiece and the heat removed from the workpiece in cool air grinding with a porous metal bonded diamond wheel (PMBDW). The following conclusions are obtained from the grinding tests: Blowing cool air onto the workpiece causes its temperature to decrease before grinding, leading to a low grinding surface temperature. Heat is removed from the grinding zone with the presence of cool air, so that the rate of heat transfer to the workpiece decreases. The amount of heat removed by cool air increases with the increase in the wheel pore rate, the increase of the wheel speed and the decrease of the table speed.

Keywords: porous metal bonded diamond wheel, grinding surface temperature, pore rate, cool air grinding, transferred heat rate, removed heat
\end{abstract}

\section{Introduction}

The grinding process requires an extremely high input of energy per unit volume of material removed. Virtually all most of this energy is converted to heat, which transfers to the workpiece, wheel and chips. The high grinding surface temperature that is produced causes various types of thermal damage and thermal deformation which lead to the reduction of accuracy. Grinding fluid has been used to reduce the grinding temperature of workpiece. However, there are some chemical substances in the grinding fluid that may be harmful to the human body and pollute the environment of the machining workshop. Cool air has been recently used to reduce the grinding surface temperature of workpiece ${ }^{1)}$. The problem is whether cool air will take heat directly out of the grinding zone or not. Moreover, it is necessary to clarify what factors influence the ability of cool air to remove heat from workpiece surface.

The present paper clarifies the influence of cool air on the heat transferred to the workpiece and the ability of cool air to remove the heat from the workpiece in cool air grinding. Especially the influence of the wheel pore rate on the ability to remove the heat from the workpiece is discussed. In addition, the influence of the grinding conditions, such as wheel speed and table speed, on the ability to remove heat is also investigated experimentally.

\section{Analytical procedures}

\subsection{Heat transferred to workpiece in dry grinding}

The percentage of heat transferred to the workpiece was previously analyzed and calculated by J.O. Outwater and M.C.Shaw ${ }^{2)}$, S.Malkin ${ }^{3)}$, K.Sato ${ }^{4)}$, and Y. Hasegawa ${ }^{5}$. It ranges from $30 \%$ (M.C.Shaw) to $70 \%$ (K.Sato and Y.Hasegawa) of the total grinding energy.

* $\quad$ Received December 10, 1999

** Graduate student, Ritsumeikan University,

$$
\text { 1-1-1 Nojihigashi, Kusatsu, Shiga 525-8577 }
$$

*** Department of Mechanical Engineering, Ritsumeikan University.

\section{Nomenclature}

$Q_{0}$ : Grinding energy $W$.

$Q_{w}, Q_{s}, Q_{c}$ and $Q_{r}:$ Heat transferred to workpiece, wheel, chips and environment $W$.

$\mathrm{V}$ : Wheel speed $\mathrm{m} / \mathrm{s}$. $\mathrm{V}_{\mathrm{f}}$ : Table speed $\mathrm{m} / \mathrm{s}$.

$\mathrm{F}_{\mathrm{t}}$ : Tangential grinding force $\mathrm{N}$.

$\mathrm{t}$ : Wheel depth of cut m. D: Wheel diameter $\mathrm{m}$.

$\mathrm{b}$ : Width of workpiece $\mathrm{m}$.

l: Length of contact area between wheel and workpiece $m$.

$$
\mathrm{I}=(\mathrm{Dt})^{1 / 2}
$$

$R_{w}, R_{s}, R_{c}$ : Transferred heat rate to workpiece, wheel and chips.

$\mathrm{V}_{\mathrm{g}}, \mathrm{V}_{\mathrm{b}}, \mathrm{V}_{\mathrm{p}}$ : Volumetric percentage of grain, bond and pore vol\%.

$\theta_{\mathrm{w}}, \theta_{\mathrm{s}}$ : Initial temperature of workpiece and wheel $\mathrm{K}$. These are temperatures of the workpiece and wheel just before grinding.

$\theta$ : Grinding surface temperature of workpiece K.

$\mathrm{T}$ : Increase temperature of workpiece $\mathrm{K}$.

$\mathrm{C}_{\mathrm{w}}$ : Specific heat of workpiece material. $\mathrm{J} / \mathrm{Kg} \cdot \mathrm{K}$.

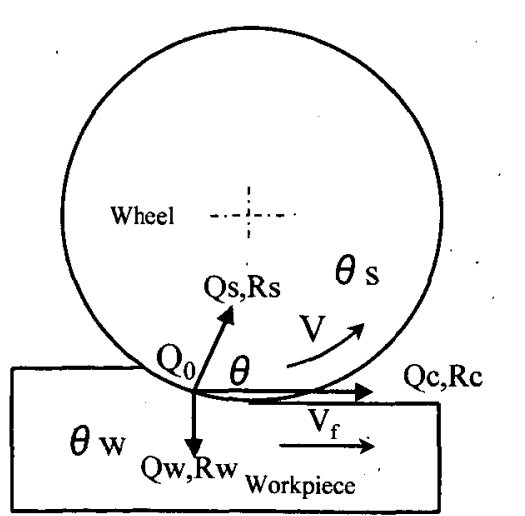

Fig. 1 Estimated distribution of grinding energy in surface grinding

In the grinding process, the energy generated by the tangential grinding force mostly transfers to the workpiece, wheel and chips $^{4)}$. The relationship between the heat transferred to the 
workpiece $Q_{w}$ and the increase of the grinding surface temperature of workpiece $\mathrm{T}$ may be defined by using M.C. Shaw's well known theory ${ }^{2}$. Under the present conditions of surface grinding of the tungsten carbide alloy of P10, this relationship is shown in Eq.(1).

$$
T=4 Q_{w} K\left\{-2.303 L \log _{10}(2 L)+1.616 L\right\} / \pi k_{w} V f b l
$$

Where $K=k_{w} / C_{w} \rho_{w}$ and $L=V_{f} / 4 K$

Here, $k_{w}$ and $\rho_{w}$ are the heat transfer coefficient and density of workpiece.

Eq.(1) shows that the increase of the grinding surface temperature of workpiece depends on the heat transferred to the workpiece $Q_{w}$. The flows of the grinding energy in surface grinding are estimated and shown in Fig. 1.

$$
\begin{aligned}
& \mathrm{Q}_{0}=\mathrm{F}_{\mathrm{t}} \mathrm{V}=\mathrm{Q}_{\mathrm{w}}+\mathrm{Q}_{\mathrm{s}}+\left(\mathrm{Q}_{\mathrm{c} 1}+\mathrm{Q}_{\mathrm{c} 2}\right)+\mathrm{Q}_{\mathrm{r}} \\
& \mathrm{Q}_{\mathrm{w}}=\mathrm{R}_{\mathrm{w}} \mathrm{Q}_{0} \quad \text { (4.1), } \mathrm{Q}_{\mathrm{s}}=\mathrm{R}_{\mathrm{s}} \mathrm{Q}_{0} \quad(4.2), \mathrm{Q}_{\mathrm{c}}=\mathrm{R}_{\mathrm{c}} \mathrm{Q}_{0}
\end{aligned}
$$

Because it is assumed that the sum of $\left(R_{w}+R_{s}+R_{c}\right)$ equals 1 , the value of $R_{w}$ in dry grinding is approximately calculated by using M.C. Shaw's theory, as shown in Eq. (5), with the initial condition $\theta_{\mathrm{w}}=\dot{\theta}_{\mathrm{s}}$ before grinding.

$$
\mathrm{R}_{\mathrm{w}}=0.752 \pi \mathrm{k}_{\mathrm{w}} /\left\{0.752 \pi \mathrm{k}_{\mathrm{w}}+\sqrt{\mathrm{k}_{\mathrm{s}} \mathrm{C}_{\mathrm{s}} \rho_{\mathrm{s}}} \sqrt{\mathrm{V}_{\mathrm{f}} \mathrm{l}} \mathrm{A}_{1}+0.752 \mathrm{C}_{\mathrm{w}} \rho_{\mathrm{w}} \mathrm{V}_{\mathrm{f}} 1 \mathrm{~A}_{1}\right.
$$

Where $\mathrm{A}_{1}=-2.303 \log _{10}(2 \mathrm{~L})+1.616$

And $k_{s}, \rho_{s}$ and $C_{s}$ are the heat transfer coefficient, density and specific heat of wheel, respectively.

\subsection{Calculation of cool air volume}

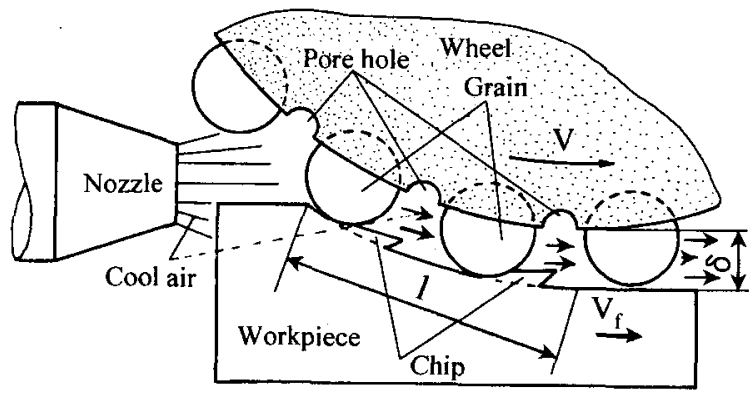

Fig. 2 Estimated model of grinding zone

When a volumetric unit of cool air blows to the workpiece in cool air grinding, a heat of $\mathrm{q}\left(\mathrm{J} / \mathrm{m}^{3}\right)$ will be taken out of the workpiece, which is called the removed heat, by the transfer from the workpiece surface to cool air. The transfer heat $q$ includes 2 parts: the transfer heat $q_{1}\left(\mathrm{~J} / \mathrm{m}^{3}\right)$ from the contact surface of workpiece and wheel to cool air and the transfer heat $\mathrm{q}_{2}\left(\mathrm{~J} / \mathrm{m}^{3}\right)$ from the workpiece surface to cool air. With the same grinding conditions and grinding energy, the removed heat $q_{2}$ from the workpiece surface to cool air is same, thus, the total removed heat will be large when the heat removed from the grinding zone to cool air $q_{1}$ is large. The removed heat $Q_{\text {re }}$ by the transfer from the contact surface of workpiece to cool air in a unit of time is calculated by the following equation:

$$
\mathrm{Q}_{\mathrm{re}}=\mathrm{q}_{1} \mathrm{~V}_{\mathrm{air}}
$$

Where $V_{\text {air }}$ is the cool air volume blown through the grinding zone in a unit of time.

In order to increase the heat removed $Q_{r e}$, it is essential to increase the cool air volume blown through the grinding zone.
Before passing through the grinding zone, pore holes are filled up by cool air from the nozzle. We also see that the time that the abrasive grains spend passing through the grinding zone is very short. Thus, only cool air in the grinding zone has the effect of removing heat out of the grinding zone. It is reasonable that the amount of heat removed has to be related with the volume of cool air passing through the grinding zone. The cool air, which passes through the grinding zone, includes:

- Cool air volume $V_{1}$ passing through the grinding zone in pore holes on the wheel surface.

- Cool air volume $V_{2}$ passing directly through the grinding zone by the blow of cool air from the nozzle.

In order to estimate the cool air volume blown through the grinding zone, the following assumptions are made:

1) The exposed heights of grains on the wheel surface after truing and dressing are the same and equal to $\delta$.

2) Each grain has a spherical shape with the radius of $r_{0}$.

3) The shape of the pores after truing and dressing is spherical and each pore hole on the wheel surface is hemispherical.

The grinding zone is estimated under these assumptions and is shown in Fig. 2. Thus, the grinding zone includes grains, chips and air. The air volume includes the air volume $v_{1}$ of the pore holes on the wheel surface, and the air volume $v_{2}$ between the wheel surface and the workpiece surface.

\subsubsection{Calculation of $V_{1}$}

The volume of the pore holes in the grinding zone $V_{\text {pore }}$ can be calculated by Eq.(8) (see appendix).

$$
\mathrm{V}_{\text {pore }}=0.816 \mathrm{bl}\left(\mathrm{r}_{0}+\delta_{0} / 2\right) \phi_{3}{ }^{3 / 2} /(\pi \lambda)^{1 / 2}
$$

Where $\delta_{0} / 2$ is the thickness of the metal coating. $\phi_{3}$ is the area percentage of pores on the wheel surface and will be defined by Eq.(9) ${ }^{6)}$.

$$
\phi_{3}=V_{p}^{2 / 3} /\left(V_{\mathrm{g}}^{2 / 3}+V_{b}^{2 / 3}+V_{p}^{2 / 3}\right)
$$

Thus, the cool air volume $V_{1}$ which passes through the grinding zone by the pore holes in a unit of time will be calculated by Eq.(10).

$$
\mathrm{V}_{1}=\mathrm{V} \times \mathrm{V}_{\mathrm{pore}} / \mathrm{l}=0.816 \mathrm{Vb}\left(\mathrm{r}_{0}+\delta_{0} / 2\right) \phi_{3}{ }^{3 / 2} /(\pi \lambda)^{1 / 2}
$$

\subsubsection{Calculation of $\mathrm{V}_{2}$}

The air volume between the workpiece surface and the wheel surface in the grinding zone $v_{2}$ is calculated by Eq.(11).

$$
v_{2}=b l \delta-\left(v_{g}+12 b l t V_{f} / V\right)
$$

Here, $\left(12 b l t V_{f} / V\right)$ is the chips volume in the grinding zone $e^{4)}$ and $\mathrm{v}_{\mathrm{g}}$ is volume of grains in the grinding zone.

The cool air volume $V_{2}$ which blows directly through the grinding zone is calculated by Eq.(12).

$$
\mathrm{V}_{2}=\mathrm{V}_{\text {air }}\left\{\mathrm{bl} \delta-\left(\mathrm{v}_{\mathrm{g}}+12 \mathrm{bltV}_{\mathrm{f}} / \mathrm{V}\right)\right\} \eta / 1
$$

Here, $\eta$ is the resistance ratio of cool air speed when blowing through the grinding zone.

\subsubsection{Cool air volume}

The total cool air volume, which blows through the grinding zone in a unit of time, $V_{t}$ will be given as follows:

$$
\begin{aligned}
\mathrm{V}_{\mathrm{t}}=\mathrm{V}_{1}+\mathrm{V}_{2}=0.816 \mathrm{Vb}\left(\mathrm{r}_{0}+\delta_{0} / 2\right) \phi_{3}{ }^{3 / 2} /(\pi \lambda)^{1 / 2} \\
+\mathrm{V}_{\text {air }}\left\{\mathrm{bl} \delta-\left(\mathrm{v}_{\mathrm{g}}+12 \mathrm{blt} \mathrm{V}_{\mathrm{f}} / \mathrm{V}\right)\right\} \eta / 1
\end{aligned}
$$

With the same wheel concentration, $v_{\mathrm{g}}$ will be same. Thus, Eq.(13) estimates that the cool air volume $V_{t}$ will be large under 
the conditions of high wheel pore rate, high wheel speed, low table speed, small wheel depth of cut and large cool air speed. However, it is difficult to calculate the volume of cool air exactly, because it is not easy to define exactly the values of $\eta$ and $\delta$. Thus, the influences of the wheel pore rate, wheel speed and table speed on the heat removed will be mainly evaluated by the experiments.

\section{Experimental procedures}

\subsection{Manufacturing of PMBDW}

The porous metal bonded diamond wheels, which has a diameter of $100 \mathrm{~mm}$ and a thickness of $8 \mathrm{~mm}$, used in the experiment have pore volumes of about $35 \%$ called low pore rate, $45 \%$ called middle pore rate, and $58 \%$ called high pore rate, and grain size of $\# 140 / 170$. The wheel pore rate varies by the change of the metal-coated thickness of $\mathrm{Ni}-\mathrm{Cu}-\mathrm{Sn}^{7}$, in order to be sure the volume of diamond is about $25 \%$. The PMBDW is sintered in a vacuum furnace under the conditions: a vacuum of 133.3 $\mathrm{Pa}$, a sintering temperature of $1173 \mathrm{~K}$ and a sintering duration of $3.6 \mathrm{ks}^{8}$. After phosphor treatment, they are heated again under the conditions of $9800 \mathrm{kPa} \times 598 \mathrm{~K} \times 10.8 \mathrm{ks}$ and treated with subzero by dipping in nitrogen liquid ${ }^{8)}$. The parameters of PMBDW are shown in Table 1.

Table 1 Parameters of PMBDW

\begin{tabular}{|c|c|c|c|}
\hline Wheel & $\mathrm{V}_{\mathrm{g}}$ vol $\%$ & $\mathrm{~V}_{\mathrm{b}}$ vol\% & $\mathrm{V}_{\mathrm{p}}$ vol\% \\
\hline $\mathrm{M} 1$ & 29.5 & 14 & 56.5 \\
\hline $\mathrm{M} 2$ & 27.6 & 26.5 & 45.9 \\
\hline $\mathrm{M} 3$ & 25.3 & 39.1 & 35.6 \\
\hline
\end{tabular}

\subsection{Cool air supply system}

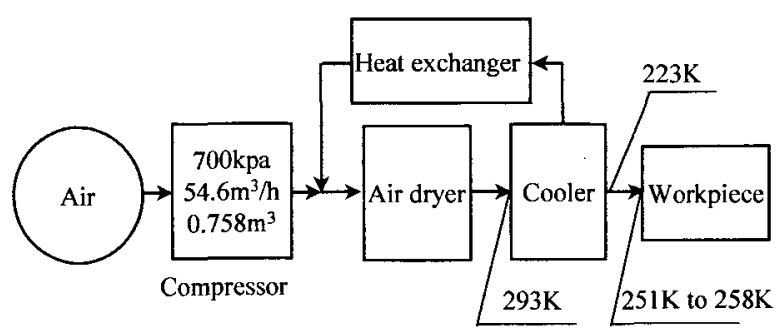

Fig. 3 Cool air. supply system

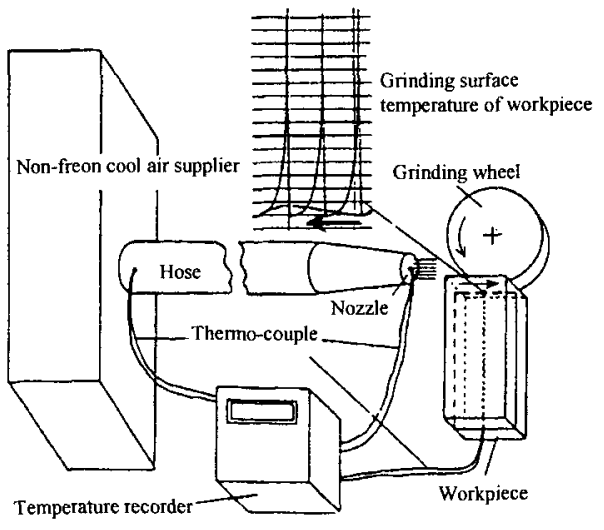

Fig.4 Measurement of temperature in grinding
The cool air supply system is shown in Fig. 3. Air is forced from the compressor to the air dryer and cooled by the cooler. The requirements of the cool air supply system are low cool air temperature and high cool air pressure. In order to achieve these requirements, a piston cooler is used for the experiment ${ }^{9}$.

\subsection{Grinding experiment}

Grinding conditions are shown in Table 2. The grinding surface temperature of the workpiece is measured by using a thermo couple of the chromel-alumel alloy, which is embedded just under the ground surface of the workpiece as shown in Fig. 4. The grinding temperature is measured when the distance from the grinding surface of the workpiece to the spot of the thermo couple is about $100 \mu \mathrm{m}$. The temperature is recorded by CHINO:AL5G55-ONN. The grinding force is measured by a dynamometer load-cell, which is connected to a computer for recording. The rate of heat transfer to the workpiece is calculated by Eq.(1) after measuring the grinding surface temperature of the workpiece.

Table 2 Grinding conditions

\begin{tabular}{|l|l|}
\hline Grinding machine & Grinding center VKC45 \\
\hline Wheel speed $\mathrm{V}$ & $20,25,30 \mathrm{~m} / \mathrm{s}$ \\
\hline Table speed $\mathrm{V}_{\mathrm{f}}$ & $60,90,120 \mathrm{~mm} / \mathrm{min}$ \\
\hline Workpiece & $\mathrm{P} 10(\mathrm{~L} 15 \times \mathrm{W} 6 \times \mathrm{H} 22)$ \\
\hline Wheel depth of cut & $2,4,6,8,10 \mu \mathrm{m}$ \\
\hline Grinding type & Down grinding \\
\hline
\end{tabular}

\section{Experimental results and discussions}

4.1 Changes of workpiece temperature and rate of heat transferred to workpiece in dry and cool air grinding

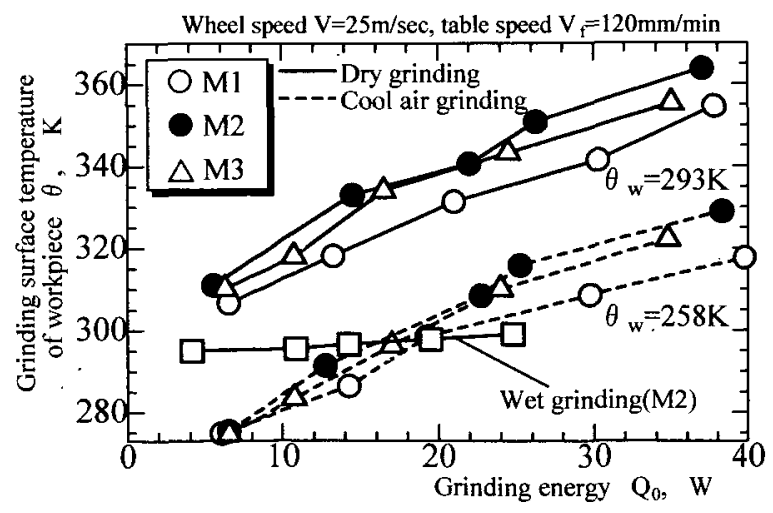

Fig. 5 Grinding surface temperature of workpiece in dry and cool air grinding

The grinding surface temperatures of the workpiece in dry and cool air grinding are shown in Fig. 5. The initial temperature of the workpiece is $293 \mathrm{~K}$ for dry grinding and $258 \mathrm{~K}$ for cool air grinding. By blowing cool air onto the workpiece during grinding, the initial workpiece temperature decreases, leading to lower workpiece surface temperatures in cool air grinding (dotted lines) than those in dry grinding (solid lines). This suggests that it is possible to obtain low grinding surface temperatures of the workpiece, just as in wet grinding, by changing the cool air temperature in cool air grinding. 


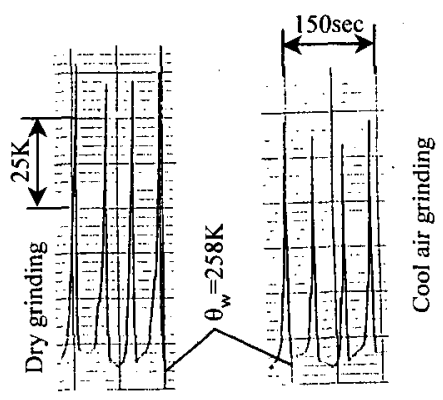

(Wheel: $M 1, V=25 \mathrm{~m} / \mathrm{sec}, V_{f}=120 \mathrm{~mm} / \mathrm{min}, \mathrm{t}=10 \mu \mathrm{m}$ )

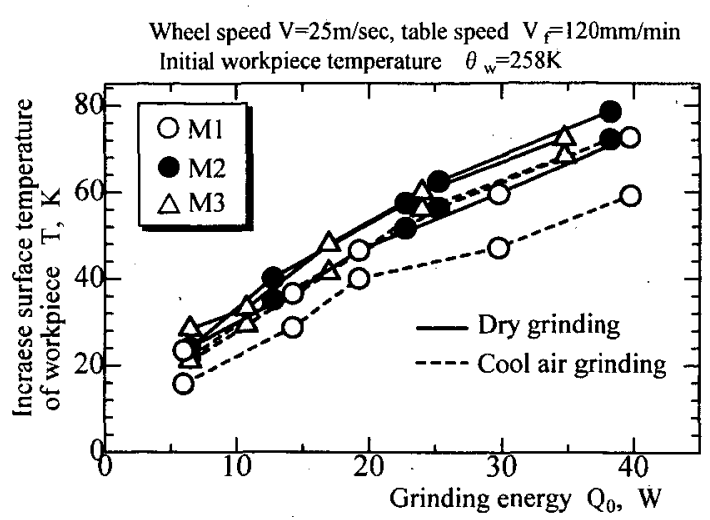

Fig. 6 Increase grinding surface temperature of workpiece in dry and cool air grinding

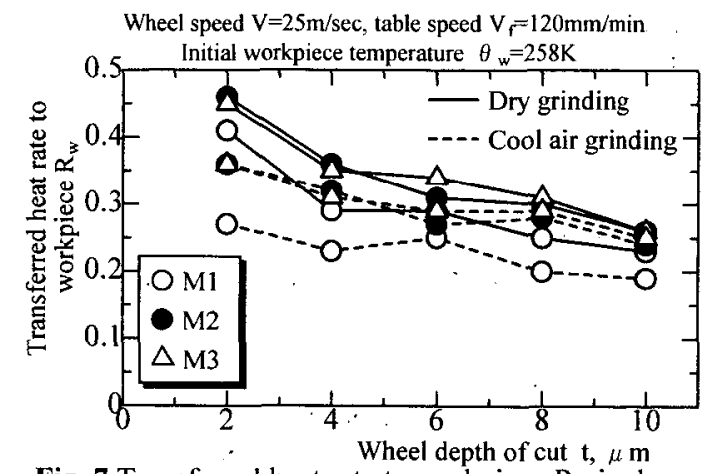

Fig. 7 Transferred heat rate to workpiece $R_{w}$ in dry and cool air grinding

Moreover, because of the high heat transfer coefficient of the metal bond, the rate of heat transferred to the workpiece will be small, leading to the low grinding surface temperature of workpiece when using PMBDW ${ }^{10)}$. Thus, the necessary temperature of cool air may be higher than that when grinding by vitrified bonded diamond wheel or resin bonded diamond wheel.

However, in order to evaluate the ability of removing heat from the grinding zone and workpiece, it is essential to consider the increase surface temperature of the workpiece. Figure 6 shows the increase grinding surface temperature of the workpiece in dry and cool air grinding with the same initial workpiece temperature $\theta_{w}=258 \mathrm{~K}$. Here, the temperature of the workpiece in dry grinding is decreased by cool air, and cool air is cut off when grinding. We can see that the increases in surface temperatures of the workpiece in cool air grinding (dotted lines) are lower than those in dry grinding (solid lines). The lower increases in surface temperature of the workpiece in cool air grinding mean that some part of the heat generated in the grinding zone is removed by cool air. Thus, the rates of heat transferred to the workpiece are smaller than those in grinding without cool air, as shown in Fig. 7. By comparing the transferred heat rate $R_{w}$ between dry grinding and cool air grinding, we can also see that the differences are larger when grinding by the wheel $\mathrm{Ml}(\mathrm{O}$ symbol), which has a high pore rate, than with the lower pore rate wheels M2 and M3. This will be clarified in the next section.

\subsection{Influence on heat removed from workpiece in cool air grinding}

\section{(1) Wheel pore rate $V_{p}$}

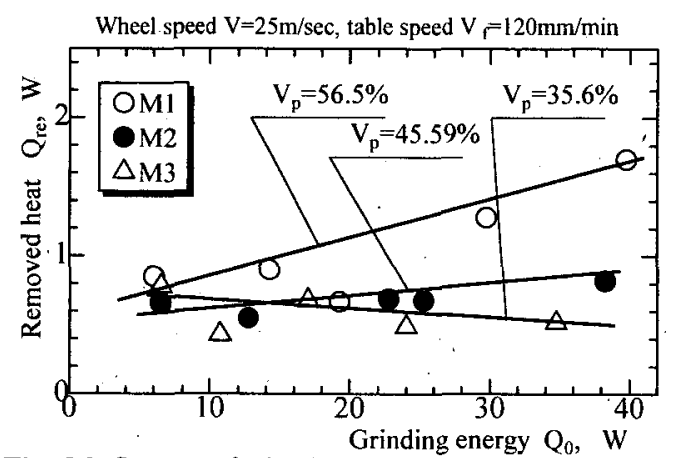

Fig. 8 Influence of wheel pore rate on removed heat out of workpiece in cool air grinding

In the grinding process, the generated heat concentrates mainly within the grinding zone for a short time $e^{11)}$. Thus, in order to increase the heat removed from the workpiece by cool air, it is essential to increase the volume of cool air which blows through the grinding zone.

From Eq.(13), one of the methods to increase the cool air volume is to use a high pore rate wheel. The ability of cool air to remove heat out of the grinding zone may be evaluated by the removed heat $\mathrm{Q}_{\mathrm{re}}=\mathrm{Q}_{\mathrm{dry}}-\mathrm{Q}_{\mathrm{cool}}$. Here, $\mathrm{Q}_{\mathrm{dry}}$ and $\mathrm{Q}_{\mathrm{cool}}$ are the heats transferred to the workpiece in dry and cool air grinding. Figure 8 shows the removed heat when grinding with three wheels which have different pore rates. We can see that the heat removed increases with the increase of the wheel pore rate. When the pore rate is high of $56.8 \%$, the metal-coated thickness is small ${ }^{7)}$ (about $8.8 \mu \mathrm{m}$ ). Thus, phosphor can deeply diffuse both to the inside of the bond bridge and to inside of the wheel with phosphor treatment. Phosphor can well diffuse into the bond bridges. After the second heat treatment, the bond bridges become hard and strong ${ }^{12)}$. After truing and dressing, the grains are highly exposed on the wheel surface. This is confirmed by observing the wheel surface by SEM photographs of grinding wheel surface after truing and dressing. From Figure 9, it is possible to see that, the value of the exposed height $\delta$ of the abrasive grain is large and there are a lot of pores on the surface of the high pore rate wheel $\mathrm{M} 1$.

On the other hand, because the pore rate is large, as shown in Eq.(9), the area percentage of pore $\phi_{3}$ is also large. From Eq.(13), the cool air volume blown through the grinding zone will be much due to the large values of $\delta$ and $\phi_{3}$. Thus, the removed heat is high. 


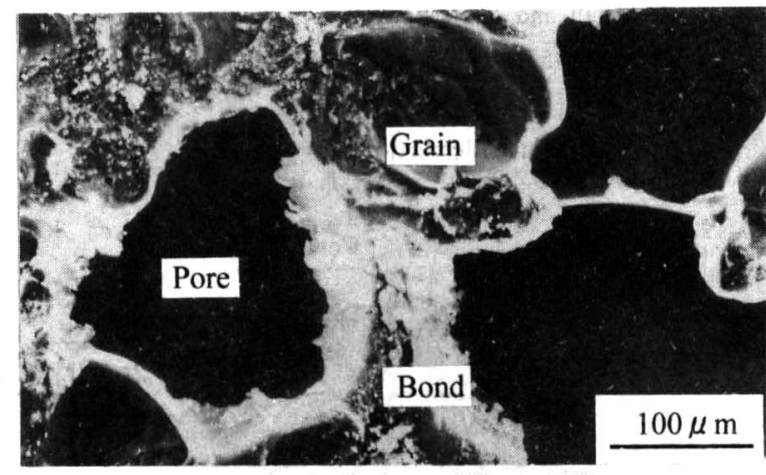

a) M1

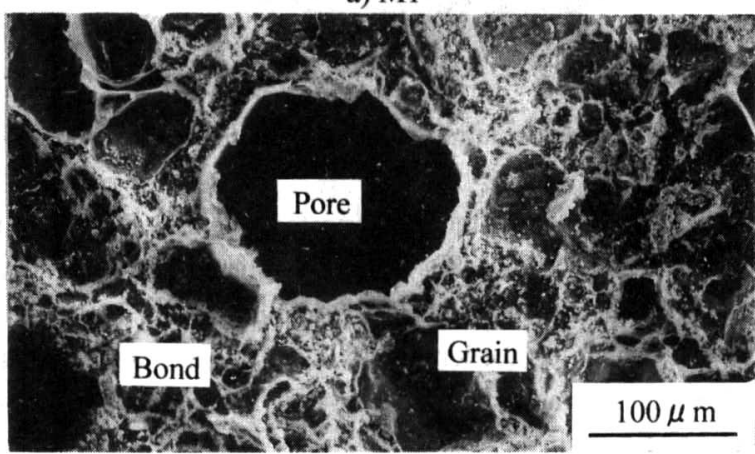

b) M2

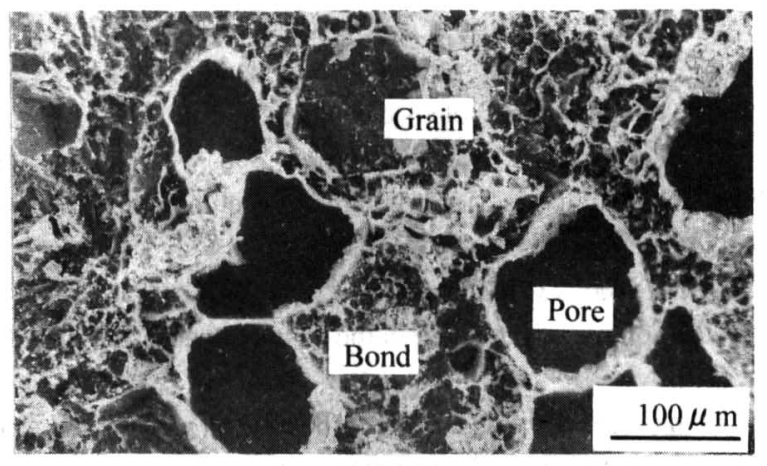

c) $\mathrm{M} 3$

Fig. 9 SEM observation of wheel surface after truing and dressing

With the middle and low pore rate wheels of $45.9 \mathrm{vol} \%$ and 35.6 vol\%, because the metal-coated thickness is large, phosphor diffuses little into the bond bridges, especially in the bond bridges inside of the wheel. After the second heat treatment and subzero treatment, the out side layer of bond bridges is hard, but the inside layer is still soft bronze. After truing and dressing, bronze has a tendency to cover the grains and to flow into the pore holes, as we can see in Fig. 9(c) (wheel M3). Thus, the grains are only slightly exposed on the wheel surface. The value of $\phi_{3}$ is also small. The lower volume of cool air blown through the grinding zone leads to the low removed heat from the workpiece, especially when wheel depth of cut is large.

\section{(2) Wheel speed V}

The influence of the wheel speed on the heat removed is shown in Fig. 10. The experimental results show that the heat removed increases when the wheel speed increases. When the wheel speed increases, the cool air volume $V_{1}$, which goes through

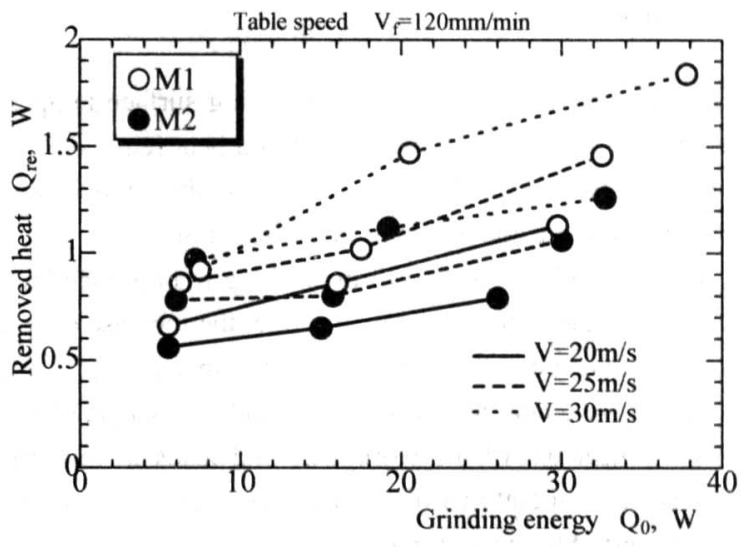

Fig. 10 Influence of wheel speed on heat removed from workpiece in cool air grinding

the grinding zone by the pores, increases as shown in Eq.(13). On the other hand, when the wheel speed is high, cool air will blow through the grinding zone more easily, and leads to an increase in the cool air volume. Therefore, much heat will be removed by cool air. In other words, the amount of heat removed increases. We can also see that the heat removed when grinding with the high pore rate wheel (M1) is much more than that when grinding by the lower pore rate wheel (M2). When wheel speed is high, however, much heat will be generated and the grinding surface temperature of the workpiece will be high.

\section{(3) Table speed $V_{f}$}

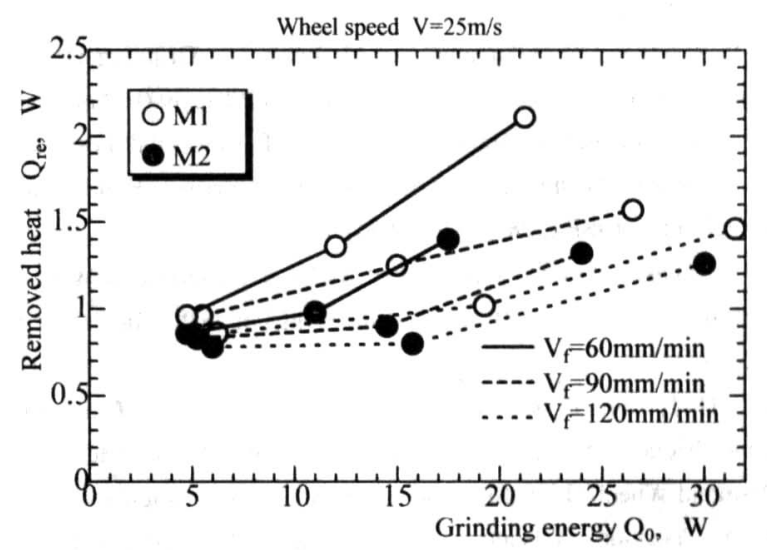

Fig. 11 Influence of table speed on heat removed from workpiece in cool air grinding

Figure 11 shows the heat removed by cool air when grinding with varied table speeds in cool air grinding. The heat removed decreases with the increase of the table speed. When the table speed is low $(60 \mathrm{~mm} / \mathrm{min})$, the volume of chips in the grinding zone is low, leading to the much air volume. Thus, the volume of cool air blown though the grinding zone is high, as shown in Eq.(13). The heat taken out of the workpiece is much. On the other hand, when the table speed is low, the grinding force is small $^{13)}$ and the grinding energy is also little. That means it is possible to obtain low heat transferred to the workpiece when the table speed is small. However, the rate of heat transferred to the workpiece will be large, as shown in Eq.(7). Thus, it is essential to consider a suitable table speed for cool air grinding. 


\section{Conclusions}

The influence of cool air on the grinding surface temperature, the heat transferred to the workpiece and heat removed from the workpiece were investigated. The following conclusions are obtained from the above results and discussions:

1) Cool air volume passed through the grinding zone increases with the increase of wheel pore rate, the increase of grinding wheel speed and the decrease of table speed.

2) By blowing cool air through the grinding zone, cool air takes some heat out of the workpiece and leads to low grinding surface temperatures of the workpiece and low rate of heat transferred to the workpiece.

3) The heat removed by cool air increases with the increase of the wheel pore rate.

4) The heat removed from the workpiece increases when the wheel speed increases and the table speed decreases.

\section{References}

1) S. Okumura, K.Yokogawa and M.Yokogawa: Study on Cool Air Grinding Technology without Fluid for Anti-Pollution Measures,J. of SGE, 41, 12 (1997) 465 (In Japanese).

2) J. O. Outwater and M. C. Shaw: Surface Temperature in Grinding, Trans. ASME, 74, 1 (1952) 73.

3) S. Malkin,: Thermal Aspects of Grinding, Part 1 - Energy Partition, Trans. ASME J. of Eng. for Ind., 96, (1974), 1177.

4) K. Sato: Machining by Grain and Wheel, Seibundou-shinkousha (1964) (in Japanese).

5) Y. Hasegawa, S. Okuyama and M. Imai: The Grinding Heat Ratio Conducted into Workpiece. J. of JSPE, 47. 10(1981) 39 (In Japanese).

6) T. Tanaka and Y. Hamuro: Analysis of Tangential Force on the Constant-load Grinding of $\mathrm{ZrO}_{2}-\mathrm{Y}_{2} \mathrm{O}_{3}$ by Vitrified Bond Diamond Wheel. Int.J.of JSPE, 28, 4 (Dec.1994) 321.

7) T. Tanaka: New Development of Metal Bond Diamond Wheel with Pore by the Growth of Bonding Bridge. Int.J.of JSPE, 26, 1(Mar.1992) 27.

8) S. H. Truong, Y. Isono and T. Tanaka; A study on the Toughening of Bond Bridge of Ni-Cu-Sn Alloy -Development of Porous Metal Bonded Diamond Wheel-, J. of JSPE, 64, 6 (1998) 923 (In Japanese).

9) Y. Yoshida, Y.Isono, T.Tanaka and Y.Morisada: Performance Interpret of Non-Freon Cool Air Supplier and Some Grinding Results, ABTEC'99 (1999) 371 (in Japanese).

10) M. W. Harris and A. S. Lavine: Thermal Aspects of Grinding: The Effect of the Wheel Bond on Heat Transfer to an Abrasive Grain, Trans. ASME for Industry, 113, (November 1991) 395.

11) S. Malkin: Grinding technology,-theory and applications of machining with abrasive-, Ellis Horwood Limited, 1989.

12) S. H. Truong, Y. Isono and T.Tanaka: Scanning electron microscopic study and mechanical property examination of a bond bridge- development of a porous metal bonded diamond wheel, J. of Material Processing Technology, 89-90(1999) 385.
13) E. R. Marshall and M.C.Shaw: Forces in Dry Surface Grinding, Trans. ASME, 74 (1952) 51.

Appendix 1: Calculation of $\mathrm{v}_{\mathbf{1}}$

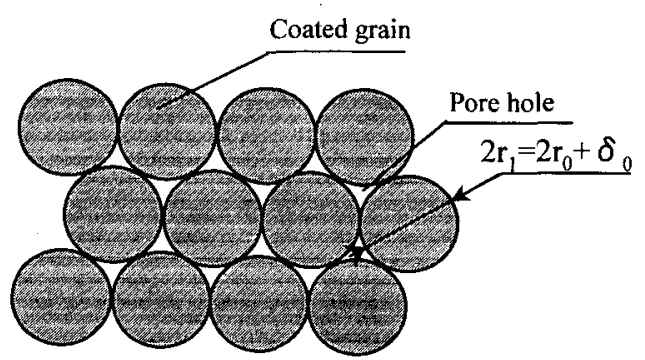

Fig. 12 Calculation model of $\lambda$ and volume of pore

The distribution of the metal-coated grains, which have the radius of $r_{1}$, in the grinding zone is estimated and shown as in Fig. 12 for the densest case. If the number of bond bridge in a unit area, which has the length equal of $1(\mathrm{~m})$ and width equal of $1(\mathrm{~m})$, is $\triangle$, the radius of pore hole is $r$. So that the area of pore in a unit of area $\left(\mathrm{m}^{2}\right)$ is:

$$
\begin{gathered}
\phi_{3}=(2 \triangle / 3) \pi r^{2} \\
r^{2}=3 \phi_{3} /(2 \triangle \pi)=3 \phi_{3} \times r_{1}{ }^{2} /\left(2 \triangle \pi \times r_{1}{ }^{2}\right)=3 \phi_{3} \times r_{1}{ }^{2} / 2 \pi \lambda \\
\text { with } \lambda=\triangle \times{r_{1}}^{2}=0.86 \quad \text { (See appendix 2) }
\end{gathered}
$$

Thus the radius of pore hole is calculated by Eq. (17):

$$
r=r_{1}\left(3 \phi_{3} / 2 \pi \lambda\right)^{1 / 2} \quad(\mu \mathrm{m})
$$

From the assumption 3 ), the volume of each pore hole $v_{1}$ on the bond is:

$$
\mathrm{v}_{1}=(1 / 2)\left(4 \pi \mathrm{r}_{1}^{3} / 3\right)=(2 / 3) \pi \mathrm{r}_{1}^{3}\left(3 \phi_{3} / 2 \pi \lambda\right)^{3 / 2}
$$

Thus the volume of pore hole in the contact zone is calculated by Eq. (19):

$$
\begin{gathered}
\mathrm{V}_{\text {pore }}=\mathrm{bl}(2 \triangle / 3) \mathrm{v}=\mathrm{bl}(2 \triangle / 3) \mathrm{v}=0.816 \mathrm{blr}_{1} \phi_{3}{ }^{3 / 2} /(\pi \lambda)^{1 / 2} \\
\text { Substitution } \mathrm{r}_{1}=\mathrm{r}_{0}+\delta_{0} / 2 \text {, the volume of pore holes is: } \\
\mathrm{V}_{\text {pore }}=0.816 \mathrm{bl}\left(\mathrm{r}_{0}+\delta_{0} / 2\right) \phi_{3}{ }^{3 / 2} /(\pi \lambda)^{1 / 2}
\end{gathered}
$$

\section{Appendix 2: Calculation of $\lambda$}

From Fig. 12, we can see that each grain at the boundary has four bond bridges, and each grain at the inside has six bond bridges. If there are $\mathrm{N}_{1}$ grains at the boundary and $\mathrm{N}_{2}$ grains at the inside in an area unit, the number of the bond bridges is:

$$
\triangle=\left(4 \mathrm{~N}_{1}+6 \mathrm{~N}_{2}\right) / 2
$$

The number of pore is $2 \Delta / 3$, the area of each pore is $0.16 \pi r_{1}^{2}$, the area of the grains is $S_{1}=\left(N_{1}+N_{2}\right) \pi r_{1}^{2}$ with $r_{1}=r_{0}+\delta_{0} / 2$. The area of pore is $S_{2}=(2 \triangle / 3) 0.16 \pi r_{1}^{2}$. Because $S_{1}+S_{2}=1$, thus:

$$
(2 \triangle / 3) 0.16 \pi r_{1}^{2}+\left(N_{1}+N_{2}\right) \pi r_{1}^{2}=1
$$

On the other hand, circumference of this area is $N_{1}\left(2 r_{1}\right)=4$, thus it is possible to define the value of $\triangle r_{1}{ }^{2}$ :

$$
\triangle r_{1}^{2}=\triangle\left(r_{0}+\delta_{0} / 2\right)^{2}=\left(3-2 \pi r_{1}\right) /(\pi+0.32)
$$

Because $r_{1}$ is very small compared with $1(\mathrm{~m})$, thus

$$
\triangle\left(\mathrm{r}_{0}+\delta_{0} / 2\right)^{2} \approx 0.86
$$

